\title{
Who benefits from HEIs engagement? An analysis of priority stakeholders and activity profiles of HEIs in the United Kingdom
}

Eva M. de la Torre ${ }^{a *}$, Federica Rossi $^{\mathrm{b}}$, Marti Sagarra ${ }^{\mathrm{c}}$

${ }^{a}$ Department of Economics and Public Finance, Universidad Autónoma de Madrid. Avda. Francisco Tomás y Valiente, 5. Campus Cantoblanco, CP 28049, Madrid, Spain.

Telephone number: +34.91.497.3555. E-mail: eva.torre@uam.es * Corresponding author

${ }^{b}$ Department of Management, Birkbeck, University of London. Malet Street, London WC1E 7HX, UK. Telephone number: +44 207 0790685. E-mail: $\underline{\text {.rossi@bbk.ac.uk }}$

${ }^{\mathrm{c}}$ Department of Business, Universitat de Barcelona. Faculty of Economics and Business. Diagonal, 690, CP 08034, Barcelona, Spain. Telephone number: +34. 93.403.9610. Email: martisagarra@ub.edu

\section{Acknowledgements}

This work was supported by a grant from Birkbeck, University of London, School of Business, Economics and Informatics. We are grateful to Cecilio Mar Molinero, Muthu de Silva and Ainurul Rosli for their very helpful comments on earlier versions of this paper. We also thank the participants to the workshop 'Universities' engagement in knowledge exchange: What do successful strategies look like?" at Birkbeck, University of London on June $29^{\text {th }}, 2016$, for their insightful comments and suggestions. 


\title{
Who benefits from HEIs engagement? An analysis of priority stakeholders and activity profiles of HEIs in the United Kingdom
}

\begin{abstract}
It has been suggested that higher education institutions (HEIs) may develop different activity profiles (including research, teaching and socio-economic engagement) in their attempt to maximise the fit between institutional resources and strategic opportunities; the latter include strategies of engagement with different groups of external stakeholders. Understanding the extent to which HEIs' resources and activity profiles are aligned with their strategic prioritisation of stakeholder groups, allows us to better understand the different ways in which HEIs drive socioeconomic development. Using non-parametric techniques - qualitative and quantitative ordinal multidimensional scaling - applied to data on the universe of HEIs in the United Kingdom, we show that HEIs with different institutional resources and undertaking different sets of activities prioritise their engagement with different stakeholder groups. We also confirm the complex associations between HEIs' institutional resources, activity profiles and stakeholder prioritisation strategies, which lock HEIs into configurations that are difficult to change.
\end{abstract}

Keywords: Higher Education (HE) differentiation; stakeholders; third mission; university engagement; multidimensional scaling (MDS); property fitting. 


\section{Introduction}

Since 1980s the role of professional management in European higher education institutions (HEIs) has increased (Schimank 2005). This shift has become much more marked in the last decade, with decision-making processes in higher education (HE) management evolving from an approach primarily based on academic consensus, with limited influence from external pressures (the university as a 'republic of scholars'), to one increasingly based on professional management and accountability, where organisational missions are shaped by numerous stakeholders, internal and external (the university as a 'stakeholder organisation'; Bleiklie and Kogan 2007). Indeed, HEIs are now expected to address the needs and expectations of a variety of stakeholders, who may be defined as any group or individual who can affect or are affected by the objectives of the organisation (Freeman 1984, 16): from internal stakeholders such as academic and administrative staff, to external stakeholders such as students, employers and policymakers (Perez-Esparrells and Torre 2013; Beerkens and Udam 2017).

The growing relevance of external stakeholders for universities owes much to the diffusion of the New Public Management approach, starting from the US in the late 1970s and progressively gaining importance in Europe and elsewhere (Olssen and Peters 2005). The New Public Management approach pushed for greater professionalisation of HEI management and greater accountability of HEIs to students and ultimately to taxpayers. This has been accompanied, since the 1990s, by the emerging policy discourse on the socioeconomic development role of HEIs, which are now expected to interact with a broad range of external stakeholders in order to trigger societal improvements and economic growth (Molas-Gallart et al. 2002). Among other designations, the engagement function of HEIs has been termed 'third mission', and it consists of the university's 'relationship with the non-academic outside world: industry, public authorities and society' (Schoen et al. 
2007, 127). It comprises knowledge transfer and innovation activities, continuing education and outreach (E3M 2012).

Over time, HEIs have been increasingly confronted with external pressures and particularly with market-type incentives (Casani et al. 2014). Accordingly, they have tended to behave strategically, choosing to particularly engage in activities where they enjoy some form of advantage over their competitors (Antonelli 2008). This has contributed to growing diversification within many HE systems, as HEIs have developed different profiles in their attempt to maximise the strategic fit between their institutional resources (subject mix, degree levels provided), activities (research and teaching intensity and quality) and the opportunities and needs in their socioeconomic contexts (Siegel, Waldman and Link 2003; Rossi 2010; Hewitt-Dundas 2012; Kitagawa, Sánchez Barrioluengo, and Uyarra 2016). These include opportunities in relation to engagement with external stakeholders, since the HEIs' 'position in the product space determines the interactions between individual organisations and the relevant audiences' (Lepori, Huisman, and Seeber 2014, 199). Such competition through mission differentiation is shaped by past policies and practice (Ntshoe 2015), but also by the expectations of stakeholders from different types of HEIs, and their willingness to accept institutional behaviours different from those of a typical HEI (Lepori, Huisman, and Seeber 2014).

So far, very few studies have explored the extent to which HEIs' resource and activity profiles - intended in a comprehensive way to include teaching, research and socioeconomic engagement - align with their strategic prioritisation of different stakeholder groups. On the one hand, HEIs' strategic behaviour has been explored mainly in relation to their teaching and research missions (Adcroft, Teckman, and Willis 2010; Bonaccorsi, Daraio, and Simar 2006; Bonaccorsi and Daraio 2008) and sometimes to third mission or engagement activities (e.g. Hussler, Picard, and Tang 2010; Hewitt-Dundas 2012), without 
considering HEIs' stakeholder prioritisation. On the other hand, stakeholder engagement has been discussed in the context of HE governance (Bleiklie and Kogan 2007; Chou et al. 2017), and with regard to the alignment of curricula to different stakeholders and particularly students (stakeholder curricula, e.g. Osborne, Davies, and Garnett 1998), but not so much in relation to HEIs' overall missions. Some studies have noted a correlation between HEIs' research and teaching profiles and their main stakeholders (Hewitt-Dundas 2012; Kitagawa, Sánchez Barrioluengo, and Uyarra 2016), but they have considered stakeholder engagement as a component of a university's third mission profile, instead of evaluating it as a separate strategy.

Our approach is original because we analyse the complex association between universities' institutional resources, stakeholder prioritisation strategies, and activity profiles, using data from the United Kingdom (UK)'s HE system. We use Multidimensional Scaling (MDS) techniques, a new method in the HE field (see Sagarra, Mar-Molinero, and Rodriguez-Regordosa 2015; Sagarra, Mar-Molinero, and Agasisti 2017; and de la Torre, Sagarra, and Agasisti 2016), to identify different university profiles based on their resource endowment and activity engagement. Unlike previous studies that focused on subsets of HEIs (Chapple et al. 2005; Curi, Daraio, and Llerena 2012; Rossi 2018), this method allows us to analyse the whole set of HEIs in the system, because it is robust to outliers and zero values, among other methodological advantages. Then, in order to study the relationships between HEIs resource and activity profiles and stakeholder prioritisation we originally combine MDS with multinomial logistic regression analysis. In this way, we are able to produce more refined HEI profiles than previous research, and we analyse empirically the potential interactions between them.

HEIs in the UK have been chosen as the focus for the empirical analysis, for several reasons. First, due to the established presence of market-type incentives, the UK is an 
instructive case for other countries where HEIs are increasingly competing with each other

for public funds, student enrolments and third mission revenues. Second, extensive data is available on UK HEIs' teaching, research and socio-economic engagement activities, thanks to comprehensive data collected by the Higher Education Statistics Agency (HESA). Data on socio-economic engagement activities are collected through the yearly Higher Education Business and Community Interaction Survey (HEBCI), which is the most comprehensive systematic data collection exercise on third mission activities available todate (Rosli and Rossi 2015).

The paper is organised as follows: Section 2 reviews the existing literature about the relationship between HEIs' prioritisation of different stakeholder groups, their institutional characteristics and their engagement in different activities. Section 3 illustrates data and methodology, while section 4 presents the results of the empirical analysis. Finally, a discussion of the results and some concluding remarks are presented in section 5.

\section{The complex relationships between HEI resources, activities and stakeholder prioritisation strategies}

HEIs are multi-stakeholder organisations with a particularly varied range of stakeholders. Their stakeholders may be classified into internal and external (Perez-Esparrells and Torre 2013). Internal stakeholders encompass HEI managers and (academic and technical and administrative) staff. They are responsible for the strategic behaviour and operational functioning of the institution: senior management is responsible for defining the objectives and targets of the HEI's missions, while middle management is responsible to ensure that the activity of the HEI fits with those objectives, and that the academic, technical and administrative staff have the necessary infrastructure and resources to develop each mission. 
External stakeholders may be classified according to their roles as (Spaapen, Dijstelbloem and Wamelink 2007): (i) policymakers, which not only employ university graduates and use research results and university courses for their own policies, but also facilitate the collaboration between HEIs and external stakeholders and provide the institutional/legal HE framework; (ii) professional users, i.e. industry and societal organisations (profit and not-profit making) that employ university graduates, seek academic training for their staff in particular professional fields, and use academic knowledge to develop products and services; and (iii) end users, understood as the public at large or individual target groups (e.g. students, farmers, disabled people) ${ }^{1}$. Students, which in the previous classification are included among 'end users', are an important stakeholder group, whose categorization is debated. In fact, they have been classified as either internal stakeholders (e.g. Marshal 2018) or external ones (e.g. Spaapen, Dijstelbloem and Wamelink 2007; Perez-Esparrells and Torre 2013) in different studies, depending on the research purpose. Since the present study examines HEIs' strategic prioritization of external stakeholders, it considers HEI from the perspective of their strategic decision-making processes, to which students are external. Hence, for our present purposes we consider students as external stakeholders.

The above-mentioned classification of external stakeholders masks different types of interactions (or roles) depending on the nature of the stakeholders. According to PerezEsparrells and Torre (2013) external stakeholders may play a financial role as funders of the HE system, donors, sponsors or funders of specific projects; they may interact with universities as clients, competitors, collaborators or partners in the HE market, or communicate the merits of the HEI (public relations perspective); and finally, HEIs may

1 For a partial review of work that has tried to provide a comprehensive list of university stakeholders see Mainardes et al. (2013. p. 434). 
interact with stakeholders or with their representatives. Table 1 contains an extensive list of HEIs external stakeholder groups classified according to their nature and their different roles in their relations with HEIs.

This table clearly shows the multi-stakeholder nature of HEIs. But the managerial challenge for HEIs is even wider, since they should also consider the scope of their relationships with their external communities: local, regional, national or international (e.g. Culum, Roncevic, and Ledic 2013). Consequently, it is impossible for HEIs to equally know, understand and address the (frequently conflictual) needs of all stakeholders, and they must prioritise some of these stakeholders as particularly important ones on which to focus their attention and engagement efforts (Mainardes et al. 2013).

\section{[Table 1] around here}

The extant literature on HEIs' stakeholders usually focuses on: (i) the adaptation of stakeholder theory to the HE context (e.g. Chapleo and Simms 2010); (ii) the identification of the HEIs' stakeholders, their characteristics and the value they add to the HE sector (e.g. Mainardes et al. 2013; Arroyo-Vazquez, van der Sijde, and Jimenez-Saez et al. 2010); and (iii) the opinion of particular stakeholders on specific HEIs' activities or initiatives (e.g. Ramirez-Corcoles and Manzaneque-Lizano 2015). Stakeholder analysis includes both studies which theorize the relationships between the HEI and its stakeholder from the viewpoint of management and organization theory, and more linear approaches, such as cause-and-effect analysis; these studies encompass a variety of qualitative and quantitative methodologies. For example, Tetrevova and Sabolova (2010) provide recommendations on strategic negotiation with individual university stakeholders; Mainardes et al. (2013) classify and rank the stakeholders of a university through a case study. Feria-Dominguez, Moreno-Carmona, and Troncoso (2013) describe the sequential process for designing and developing strategic plans based on prioritising specific stakeholders to analyse their 
interests and needs and finally define the activities to meet the strategic goals tied to the targeted groups. Mampaey and Huisman (2016) analyse defensive strategies to stakeholders of research intensive European universities through a case study. Labanauskis and Ginevičius (2017) also use the case study method to analyse the role of stakeholders in the development of HEIs services.

However, while these studies focus on the relevance of different stakeholders to HEIs, they do not analyse the extent to which these are aligned to the HEIs' broader resources and activity profiles; they also tend to focus on one or a few institutions, rather than adopt a sector-wide perspective. Some studies that describe the socio-economic engagement profiles of HEIs in UK have demonstrated such alignment, but as a side result rather than as the main focus of the analysis, and often considering stakeholder engagement as part of the HEI's third mission profile, rather than as a separate strategic decision. Hewitt-Dundas (2012) distinguishes between high research intensity (HRI) and low research intensity (LRI) HEIs in the UK, and explores how these differ in their capability to deliver engagement activities, the scale of these activities, and their partners. The two groups are found to engage in very different activities: HRI are more likely to develop and exploit intellectual property (IP) and to maximise returns on research, and engage mostly with partners outside the region, while LRI stress their potential contribution to human capital development, and mostly interact with partners within the region. These findings have been confirmed by a qualitative study of HEIs' strategic documents (Kitagawa, Sánchez Barrioluengo, and Uyarra 2016) which shows how institutions with different research and teaching intensity engage in different activities aimed at different partners and with different geographical scope. Schoen et al. (2007) indicate that European HEIs providing only undergraduate and master level education mainly focus on the fit between curricula and local employment needs; while those providing education, research and 
academic training (doctoral degrees) develop engagement activities related to universityindustry research, IP rights, spinoff companies and participation in public debates. Moreover, case studies have shown that while HEIs that are specialised or oriented towards engineering, natural sciences or information technology mainly focus on business and industry partners, researchers in the humanities, arts and social sciences usually interact with public bodies, non-profit organisations, and other community groups with lower purchasing power (Benneworth and Jongbloed 2010).

Still, the specific links between the HEIs' resources, their choice of activity (and socio-economic engagement) profiles, and their strategies in terms of prioritisation of different stakeholder groups, have not been explored in detail. This study aims to fill this gap in research by investigating whether HEIs in a specific HE system adopt differentiated activity profiles (including teaching, research and engagement activities), and how these activity profiles relate to their institutional resources and align with their strategies of prioritising different groups of stakeholders. As the linkages between these are not unidirectional and are mediated by HEI characteristics as well as other strategic choices, the analysis does not aim to uncover precise causal relationships but to explore the nature of the association between them.

In particular, we argue that the linkages between the HEI's institutional resources, its strategies (including those pertaining to stakeholder prioritisation) and the development of its specific activity profile are multiple and complex, and that each element influences all the others, as the simple diagram presented in Figure 1 illustrates.

\section{[Figure 1] around here}

On the one hand, the HEI's institutional resources, including its research intensity and subject specialisation, jointly influence both the types of activities that the HEI engages in, and the stakeholders it responds to. In fact, the characteristics of universities in terms of 
research intensity, subject mix, endowment of capital and labour resources, are strongly path dependent and tend to influence both the types of stakeholders they traditionally interact with (Jongbloed, Enders, and Salerno 2008) (linkage A in Figure 1), and the range of socio-economic engagement activities they can perform more effectively and efficiently (linkage B in Figure 1), which will also attract specific types of stakeholders (e.g. Thursby and Kemp 2002). But these associations are bi-directional: the activity profiles of HEIs also determine the potential resources they may raise (linkage B in Figure 1), and stakeholders can also influence the resources of a HEIs since they may be funders, donors, policymakers, etc. (linkage A in Figure 1).

Hence, we expect to find a close association between HEIs' institutional resources and their priority stakeholders (A), and between HEIs' institutional resources and their activity profiles (B).

Additionally, HEIs may strategically choose to prioritise certain stakeholders as opposed to others, for example in order to intentionally maximise their income from certain activities (Kitagawa, Sánchez Barrioluengo, and Uyarra 2016), leverage their complementary organisational strengths (Ankrah et al. 2013) or increase their influence vis a vis particular socioeconomic constituencies. Not all stakeholders are equally salient for HEIs and the evolving university-social interaction may change the importance of each stakeholder over time (Benneworth and Jongbloed 2010). The diversity of HEIs entails that different institutions will engage with different stakeholders, which then influences directly the type of activities they perform (linkage $\mathrm{C}$ in Figure 1). These activity profiles include not only the HEIs' decisions to engage in specific research and teaching activities but also, perhaps even more strongly, their decisions to engage in specific third mission activities which by definition involve external stakeholders. Once again, the relationship may be bidirectional, since the activities traditionally performed by HEIs may determine the potential 
stakeholders they could address. Hence, we expect to find an association between priority stakeholders and activity profiles (C).

\section{Data and methodology}

\subsection{Data sources}

This study profits from the large amount of data available in the UK about HEIs' engagement in research, teaching and third mission activities. We integrate HEBCI data with general HESA data on HEIs' teaching and research engagement as well as other institutional characteristics, together with Scopus and ISI data on publications in order to consider their different coverage for different subject mixes (our methodological approach allows for including both variables). Our dataset consists of information for the academic year 2013/14 on 159 out of the 165 HEIs that submit entries to the HEBCI. Only six HEIs have been excluded from the sample: four universities that have recently merged with other institutions and no longer exist independently, as well as two institutions that are federations of colleges. The size of the sample is one of the strengths of this paper: extant empirical studies on HEIs' socio-economic engagement profiles usually drop a large share of the population due to methodological restrictions that our empirical approach overcomes (Curi, Daraio and Llerena 2012; Rossi 2018).

\subsection{Methodological approach}

We first examine both the HEIs' profiles with respect to their activities and resources, and their stakeholder prioritisation strategies. We later investigate the association between these aspects. For the identification of the activity profiles and stakeholder prioritisation strategies, we rely on MDS (Kruskal 1964; Kruskal and Wish 1978), a robust data mining technique based on non-parametric and distance-based multivariate analysis. In particular, 
we ran two parallel analyses: (i) we use quantitative MDS to categorise HEIs' resource and activity profiles; and (ii) we rely on qualitative MDS to categorise HEIs' stakeholder prioritisation strategies.

MDS is a new technique in the HE field that reduces the dimensionality of the data and produces statistical maps: if the similarity between two HEIs is high they are placed next to each other in the map, and if the similarity is low they are placed far apart. In this way, the coordinates that each HEI would get in the $m$-dimensional MDS map indicate their degree of similarity with regard to the original data. Quantitative MDS deals with quantitative data and relies on Euclidian distances. Qualitative MDS works with binary variables, and relies on the Russell and Rao (1940) measure of proximity, in which equal weight is given to matches and non-matches: the higher the number of coincidences, the more similar the HEIs.

MDS has a number of advantages that allow us to develop more refined categorisations of both stakeholder prioritisation strategies and activity profiles compared to those introduced by previous research: (i) MDS analyses together variables and observations; (ii) it is robust to redundant variables, allowing for a high number of variables by grouping them in few dimensions; (iii) it is robust to the presence of outliers and zero values; (iv) it can work with several measures of proximity; and (v) it does not assume a normal data distribution. Consequently, MDS can be applied to the universe of the HEIs in the sector and fully accounts for its heterogeneity and diversity.

Following the MDS literature (see Sagarra, Mar-Molinero, and RodriguezRegordosa 2015: Sagarra, MarMolinero, and Agasisti 2017; and de la Torre, Sagarra, and Agasisti 2016), in the case of the quantitative MDS analysis, we apply hierarchical cluster analysis (Ward's method) on the MDS coordinates, identifying those HEIs that are close to each other in the multi-dimensional configuration (i.e. they have similar resources and 
activity profiles). Since these profiles are built on the basis of the MDS coordinates we overcome the limitations of cluster analysis, because the MDS technique would have already dealt with outliers and redundant information.

Additionally, in the case of the qualitative MDS analysis, we use the property fitting technique to interpret the resultant dimensions of the MDS construct. Property fitting (ProFit) is a technique that relies on linear or logistic regression and that comes under the general umbrella of biplots (Gower and Hand 1996; Mar-Molinero and Mingers 2007). It consist on running parallel regressions (one for each variable initially included in the MDS analysis) in which the original variables (dependent variables) are regressed on their MDS coordinates (independent variables). The resultant directional cosines of the regression indicate the correlation between the original variables and the MDS dimensions, providing information on their meaning and allowing for their interpretation. These dimensions would identify different stakeholders addressed by HEIs.

Finally, to assess the association between HEIs' resources and activity profiles and stakeholders prioritisation strategies, we use multinomial logistic regression analysis. Multinomial logistic regression consists on a linear regression analysis in which the dependent variable is nominal with more than two categories, which allows us to deal with multiple outcomes. In our analysis, the dependent variable is a categorical variable associating each HEIs to its cluster (derived by clustering the quantitative MDS coordinates). As independent variables, we use the coordinates from the qualitative MDS analysis on HEIs' stakeholder prioritisation strategies.

\subsection{Variables selection}

In order to identify different HEI profiles, we apply a quantitative MDS algorithm to the variables listed in Table 2 . The 19 variables in Table 2 portray a complete 
characterisation of HEIs in terms of their activities (teaching, research, socio-economic engagement) and their main resources (nature of funding, subject specialisation). These include, in particular: (i) teaching engagement - characterised by the relative prevalence of undergraduate with respect to postgraduate teaching; (ii) research engagement - including the research productivity of HEIs and the weight of research students in the total student body; (iii) third mission engagement - seven variables representing HEIs' breadth of engagement in third mission activities: income from research contracts, income from consultancy contracts, income from courses for professional development (CPD), regeneration income, academic days spent on public engagement, number of patents filed and number of spinoffs created; (iv) funding model - measured in terms of the reliance on structured personnel (share of full time equivalent faculty) and reliance on public funding (share of income coming from government grants); and (v) subject mix. To eliminate size bias, all variables are expressed as ratios. We consider these 19 variables to contain enough information to approximate the heterogeneity of the UK HE system, while at the same time being parsimonious enough to make it possible to interpret the results without making the analysis too cumbersome.

In order to identify different HEI stakeholder prioritisation strategies, we then apply a qualitative MDS algorithm to the variables listed in Table 3. Following our theoretical framework, these variables summarise information from HEBCI on the stakeholders that the HEI prioritises, in terms of their sector (distinguishing between commercial, noncommercial and public sector partners), their nature (students, employers, industry and local communities) and their geographical location (national or international, regional, local).

HEIs prioritising students focus on: widening participation/access; helping with student and graduate enterprises; attracting non-local students to the region; graduate 
retention in local region. HEIs prioritising employers focus on: meeting regional skills needs; meeting national skills needs; and management development. HEIs prioritising industry stakeholders are oriented towards: knowledge exchange; research collaboration with industry; commercialisation (e.g. spinoff activity/licensing); provision of incubator support; and supporting small and medium size enterprises (SMEs). Finally, HEIs prioritising local communities intend to: attract inward investment to region; support community development; develop local partnerships; and facilitate networks.

As for geographical scope, National and international indicates whether HEIs prioritise: meeting national skills needs; international EU needs; or other international needs. Regional describes HEIs that have chosen to pursue: meeting regional skills needs; attracting non-local students to the region; graduate retention in local region; attracting inward investment to region; regions; and devolved Government region. Finally, Local approximates HEIs that prioritise: support for community development; developing local partnerships; local authority area; and locality. These are binary variables that indicate whether a particular HEI strategically prioritises the needs of a specific stakeholder group.

\section{[Tables 2 and 3] around here}

\section{Results}

\subsection{Identification of HEIs' resource and activity profiles}

In order to identify HEIs' resource and activity profiles we first obtain the MDS coordinates for the 19 variables listed in Table 2. Looking for balance between the goodness of fit and the complexity of the model - both increasing with each additional dimension - we consider that the optimal MDS solution is the one producing six 
$\operatorname{dimensions}^{2}$.

Through a cluster analysis of the 159 HEIs using their six MDS coordinates as variables, we obtain six clusters, two of them consisting of one outlier. Given the limited number of outliers and their specialised nature ${ }^{3}$, we focus the rest of our discussion and analysis on the four main clusters.

Table 4 differentiates the four main clusters on the basis of the 19 variables on which the MDS was performed and the nature of their HEIs. The Kruskal-Wallis test suggests that the differences in means across clusters are significant (except for the variable Share_income_public, which does not discriminate well between the different activity profiles). A complete list on the HEIs belonging to each cluster is available in Appendix 1. The fact that the four clusters are clearly differentiated in terms of their activities and their institutional resources shows that there is an association between activity profile and resources (mainly in terms of subject mix), as we expected (linkage A in Figure 1). This is also confirmed by the high correlations between activity and resource variables (the Pearson correlation coefficients between these variables are presented in Appendix 2).

Cluster 1 is composed of 8 HEIs that have very high numbers of patents and income from research contracts, very high values of the research-related variables and low values of the teaching-related ones, and high shares of staff in medicine and science and engineering: these are highly research-intensive universities that follow a 'research

2 A seventh dimension improves very little the goodness of fit of the configuration, and it would render the interpretation of results more difficult. The results of this analysis are available in a technical annex upon request to the corresponding author.

3 These outliers are the both strongly specialised institutions, one in business (the London Business School) and one in tropical medicine (the Liverpool School of Tropical Medicine). 
commercialisation' activity approach. They are all old universities founded before the 1990s. We call these 'science-based highly research intensive' universities (SHRI).

Cluster 2 is composed of 54 HEIs that have relatively high patents, income from research, consultancy and regeneration programmes, high value of the research-related variables, and relatively low students per academic, as well as a high share of staff in science and engineering. These are also research-intensive universities, but less so than those in the previous cluster, and they have a more mixed socio-economic engagement profile since they also engage in consultancy and regeneration programmes. We call these 'mixed profile research intensive' universities (MPRI). The largest majority (89\%) are old universities, founded before the 1990s.

Cluster 3 includes 55 universities with high income from CPDs and high values of the teaching-related variables. They have quite a substantial share of staff in social sciences. The majority are former polytechnics $(62 \%)$, that is, institutions mainly founded in the XIX and early XX century that provided vocational education in a range of applied subjects (like agriculture, nursing, some applied engineering fields and teaching). Polytechnics received university status in 1992. About a third (28\%) are modern universities founded after 1990. We call these 'professional teaching intensive' universities (PTI).

Cluster 4 includes 40 universities with high involvement in public engagement, high values of the teaching-related variables, and a very high share of staff in arts and humanities; they are mostly HE colleges, which provide education in the arts such as music conservatoires and schools of fine and performing arts (40\%) but also modern universities founded after $1990(30 \%)$. We call these 'arts and humanities-based teaching intensive' universities (AHTI). 
These results are consistent with, and further refine, those of Hewitt-Dundas (2012), who stated that highly research intensive HEIs engage in IP exploitation activities, while low research intensive HEIs stress their potential contribution to human capital development.

\subsection{Identification of HEIs' stakeholder prioritisation strategies}

To analyse the main alternatives strategically chosen by HEIs' regarding stakeholder prioritisation, we perform a qualitative MDS analysis using the binary variables showed in Table 3. We consider the solution of five dimensions as the optimal one, since the corresponding Stress-1 value (0.0386) is considered as 'excellent' in Kruskal's (1964) verbal classification, and the addition of a sixth dimension improves very little the goodness of fit of the configuration. Further results of this analysis are available in a technical annex upon request to the corresponding author.

Table 5 shows the R2 from ProFit analysis, as well as the correlations (directional cosines) between the original variables and the MDS dimensions. According to Table 5, Dimension 1 negatively correlates with the variables related to commercial private business, and industry. This suggests that Dimension 1 could be interpreted as 'not prioritising commercial private industry stakeholders'. Dimension 3 is associated with the variables related to employers and local communities, as well as to national and international geographical priorities. This suggests that Dimension 3 could be labelled as 'prioritising employers'. Dimension 2 differentiates those HEIs attending the need of international employers from those prioritising local communities. Dimension 2 may then be labelled as 'prioritising local community'. Finally, Dimension 4 is clearly associated to 'prioritising students' and Dimension 5 is negatively associated to non-commercial partners, suggesting that it can be interpreted as 'not prioritising non-commercial partners'. 


\subsection{Alignment between resource and activity profiles and HEIs' stakeholder prioritisation strategies}

In this section, we explore whether the four clusters previously identified differ in terms of the stakeholders that HEIs prioritise strategically. Table 6 disaggregates the information about HEIs' priority stakeholders, according to the four clusters produced in the previous section. While SHRI and MPRI institutions mainly prioritise commercial private business as partners, AHTIs focus on non-commercial social, community and cultural organisations, and PTI prioritise either commercial private business or public sector (commercial and noncommercial) organisations as their partners/clients. Furthermore, while SHRI and MPRI institutions focus their greatest contribution to economic development on industry and, to a lesser extent, on employers, the focus of PTI and AHTI is more diversified on all stakeholder groups. Students and local communities areas gradually increase their role when moving from Cluster 1 to Cluster 4, while industry shows the opposite pattern. This is interesting insomuch as it suggests that not all HEIs are equally equipped and prepared to interact with industry, and that initiatives designed to get HEIs to work with business (such as the introduction of Apprenticeship Degrees which include a combination of work placement and academic study) might not work with all of them - a point to which we will return in the Conclusions. Finally, SHRI and MPRI institutions prioritise mainly the national and/or international and regional areas respectively, while PTI and AHTI institutions focus on the regional and local areas, which gradually increase their importance when moving from Cluster 1 to Cluster 4.

To better understand how different resource and activity profiles align with HEIs' prioritisation of different stakeholder groups, we perform a multinomial logistic regression 
analysis. We use as dependent variables the HEIs' resource and activity profiles, and as independent variables the five different dimensions of the HEIs' priority stakeholders. In this way, we further analyse their association. The results are shown in Table 7 - the PTI cluster was selected as base outcome to which the other clusters are compared.

The variable Not prioritising industry presents statistical significance in all the different outcomes, indicating that the prioritisation (or lack thereof) of industry stakeholders' has a strong discriminating effect on the HEIs resource and activity profiles. The signs of the coefficients confirm our expectations: while SHRIs and MPRIs are more oriented towards industry partners compared to PTI institutions (i.e. one expects a greater likelihood of being either a SHRI or a MPRI by a HEI with a more negative value in the variable Not prioritising industry), AHTIs are less oriented in this sense. Considering that we use multinomial logistic regression, the computation of marginal effects gives us a more reliable notion of how much the probability of having a specific resource and activity profile increases given a specific variation in the explanatory variables (i.e. dimensions). Therefore, in the case of AHTIs, a marginal effect of the Not prioritising industry variable equal to 0.483 means that when this variable increases by one unit, the probability of having such profile will increase by $48.3 \%$, when all the other variables are controlled for. On the other hand, the variable Prioritising employers presents statistical significance for the MPRI and AHTI outcomes only (although with different signs, negative and positive respectively), considering the PTI as the base outcome. Finally, Prioritising students and Not prioritising non-commercial only discriminate the AHTI profile.

These results confirm our expectation that there is a strong association between stakeholder prioritisation strategies and resource and activity profiles (linkages B and C in Figure 1). The results are consistent with previous studies using data from the UK, which concluded that HEIs with high research intensity tend to interact with larger firms and more 
distant partners, while those with low research intensity mainly interact with SMEs and more local partners (Hewitt-Dundas 2012; Kitagawa, Sánchez Barrioluengo, and Uyarra 2016). Our theoretical framework and results go a step further, indicating that activity profiles are associated with institutional resources and with institutional strategies including stakeholder prioritisation. In particular, prioritising or not business/industry stakeholders or employers seem to be key factors in the final configuration of the activity profile of HEIs in the UK.

[Tables 6 and 7] around here

\section{Conclusions}

This study explores the nature of the association between stakeholder prioritisation and development of HEIs' resource and activity profiles in UK. Results provide a more refined categorisation of activity profiles than previous attempts. They indicate that UK HEIs have very varied resource and activity profiles, distinguishing between: (i) 'science-based highly research intensive' universities (SHRI) (ii) 'mixed profile research intensive' universities (MPRI); (iii) 'professional teaching intensive' HEIs (PTI); and (iv) ‘arts and humanitiesbased teaching intensive' HEIs (AHTI).

There appears to be a consistent pattern, as we expected, between institutional resources and activities performed: SHRI and MPRI profiles are more likely to be old universities and to specialise in medicine and science and engineering, HEIs with a PTI profile are more likely to be former polytechnics or modern universities and to specialise in the social sciences, and AHTI are more likely to be higher education colleges or modern universities and to specialise in the arts and humanities. Moreover, there is an association between the teaching and research activities of HEIs and their socio-economic engagement profiles, with more research intensive universities focusing on patenting and research 
contracts and teaching intensive universities focused on CPD and public engagement which is consistent with previous results for the UK (Hewitt-Dundas 2012; Kitagawa, Sánchez Barrioluengo, and Uyarra 2016).

Finally, we find that stakeholder prioritisation strategies are strongly associated with resource and activity profiles. The choice between prioritising business/industry stakeholders and employers are key factors in the final configuration of the activity profile of HEIs, with universities prioritising industry stakeholders more likely to have a SHRI or MPRI profile and those prioritising employers more likely to have an AHTI profile.

These results reflect, to some extent, the longstanding division between universities and former vocational education institutions (polytechnics) which, although legally abolished in 1992, still impacts the UK HE population structure (Lepori, Huisman, and Seeber 2014; Croxford and Raffe 2015). This persistent pattern can be explained by the complex associations (highlighted in our conceptual model) between strategic prioritisation of stakeholders and institutional resources and activities. The stakeholders a HEI serves are strongly influenced by its strategies but also by its resources and activities, and each of these different dimensions in turn shapes the others. Therefore, HEIs are very likely to be 'locked' for a long time in such configurations of resources, activities and priority stakeholders, due to the strong mutual interdependence of these dimensions; this in turn creates strong path dependency in the system, where HEIs' historical configurations still impact their current ones.

At the same time, such interdependence also entails that a change in any of these elements may trigger transformations in the other dimensions. The identification of such signs of transformation, including at an early stage of the process, is a potential field for future research in HE. 
Our findings suggest a number of implications. First, stakeholder prioritisation strategies are very likely to be strongly constrained by resource and activity profiles, which tend to take a long time to change, with respect to the shorter times involved in strategymaking. So changing priority stakeholders is likely to prove quite difficult, given the high degree of inertia and path dependency of the other interdependent dimensions. For example, if a professional teaching intensive HEI decided to prioritise their relationship with industry researchers outside the region, they might find this quite difficult to accomplish, because their resources and activities would lead them to privilege local stakeholders and particularly employers. However, if they succeeded, this would have implications in their resource and activity profiles, getting them closer to science-based highly research intensive or mixed profile research intensive HEIs in the medium-long term. HEIs' strategic decisions should take into account such dynamics when defining objectives and expected results, as well as the current stakeholder-resource-activity configuration of the HE sector in the UK.

Second, since HEIs are so different they cannot be expected to respond in the same way to the same incentives. Policies aimed at supporting engagement with certain types of stakeholders will only work if the institutional configuration is favourable to developing that kind of engagement. For example, highly research intensive universities that attract internationally mobile graduates would not be strongly receptive to policies aimed at helping universities to improve their graduates' local employment prospects. Policymakers, should bear in mind the stakeholder-resource-activity profiles in order to design effective initiatives.

While the study relies on UK data, the findings more generally illustrate how, in an established public HE system subject to strong market-type incentives, HEIs' activity profiles are based on the alignment among teaching, research and socio-economic 
engagement, and they are also aligned with different stakeholder prioritisation strategies. Therefore, our analysis reveals the patterns of diversification of activity and stakeholder profiles that are likely to emerge in HE systems that are subjected to similar pressures. Similar analyses using data from other national HE systems would be instructive.

Further research could aim to develop more fine-grained distinctions, for example by applying MDS to department-level data in specific subject areas - although data at this level are less easily available. A causal analysis identifying the additional factors determining the profile of HEIs should provide valuable information on their production processes. Finally, a longitudinal analysis would allow to identify whether and how HEIs' activity profiles have changed over time, and if so whether certain profiles are becoming more widespread, or whether profiles are changing in particular directions.

\section{References}

Adcroft, A., Teckman, J., and Willis, R. 2010. "Is higher education in the UK becoming more competitive?" International Journal of Public Sector Management 23(6): $578-588$.

Ankrah, S.N., Burgess, T.F., Grimshaw, P., and Shaw, N.E. 2013. "Asking both university and industry actors about their engagement in knowledge transfer: What singlegroup studies of motives omit”. Technovation 33(2-3): 50-65.

Antonelli, C. 2008. "The new economics of the university: a knowledge governance approach". Journal of Technology Transfer 1(33): 1-22.

Arroyo-Vazquez, M., van der Sijde, P., and Jimenez-Saez, F. 2010. "Innovative and creative entrepreneurship support services at universities”. Service Business 4(1): 63-76.

Beerkens, M., and Udam, M. 2017. "Stakeholders in higher education quality assurance: Richness in diversity?”. Higher Education Policy 30(3): 341-359.

Benneworth, P., and Jongbloed, B. 2010. "Who Matters to Universities? A Stakeholder Perspective on Humanities, Arts and Social Science Valorization". Higher Education 59: 567-588. 
Bleiklie, I., and Kogan, M. 2007. "Organization and Governance of Universities". Higher Education Policy 20(4): 477-493.

Bonaccorsi, A., and Daraio, C. 2008. "The Differentiation of the Strategic Profile of Higher Education Institutions. New Positioning Indicators Based on Microdata". Scientometrics 74(1): 15-37.

Bonaccorsi, A., Daraio, C., and Simar, L. 2006. "Advanced indicators of productivity of universities: an application of robust nonparametric methods to Italian data". Scientometrics 66(2): 389-410.

Casani, F., De Filippo, D., García-Zorita, C., and Sanz-Casado, E. 2014. "Public versus private universities: Assessment of research performance; case study of the Spanish university system". Research Evaluation 23: 48-61.

Chapleo, C., and Simms, C. 2010. "Stakeholder analysis in higher education: A case study of the University of Portsmouth". Perspectives: Policy and Practice in Higher Education 14(1): 12-20.

Chapple, W. Lockett, A., Siegel, D., and Wright, M. 2005. “Assessing the relative performance of U.K. university technology transfer offices: parametric and non-parametric evidence". Research Policy 34: 369-384.

Chou, M.H., Jungblut, J. Ravinet, P., and Vukasovic, M. 2017. "Higher Education Governance and Policy: Multi-issue, Multi-level, and Multi-actor Dynamics”. Policy and Society 36(1): 1-15.

Croxford, L., and Raffe, D. 2015. "The iron law of hierarchy? Institutional differentiation in UK higher education". Studies in Higher Education 40(9): 1625-1640. doi: 10.1080/03075079.2014.899342.

Culum, B., Roncevic, N., and Ledic, J. 2013. "Facing New Expectations - Integrating Third Mission Activities into the University”. In The Academic Profession in Europe: New Tasks and New Challenges, edited by B. Kehm, and U. Teichler, 163-196. Dortrecht, Heidelberg, London, New York: Springer.

Curi, C., Daraio, C., and Llerena, P. 2012. "University technology transfer: how (in)efficient are French universities?” Cambridge Journal of Economics 36: 629-654.

de la Torre, E.M, Sagarra, M., and Agasisti, T. 2016. “Assessing Organizations' Efficiency Adopting Complementary Perspectives: An Empirical Analysis Through Data Envelopment Analysis and Multidimensional Scaling, with an Application to Higher 
Education". In Handbook of Operations Analytics Using Data Envelopment Analysis, edited by S.N. Hwang, H,S, Lee, and J. Zhu, 145-166. New York: Springer.

E3M. 2012. Green Paper: Fostering and Measuring 'Third Mission' in Higher Education Institutions. E3M: European Indicators and Ranking Methodology for University Third Mission.

Feria-Dominguez, J.M., Moreno-Carmona, C., and Troncoso, A. 2013. Stakeholder approach versus Product-Service approach: an innovative application to the Strategic Planning for Universities. 6TH International Conference of Education, Research and Innovation (ICERI).

Freeman, R. E. 1984. Strategic management: A stakeholder approach. Boston, MA: Pitman.

Gower, J.C., and Hand, D.J. (1996) Biplots. London: Chapman \& Hall.

Hewitt-Dundas, N. 2012. "Research intensity and knowledge transfer activity in UK universities". Research Policy 41: 262-275.

Hussler, C., Picard, F., and Tang, M.F. 2010. "Taking the ivory from the tower to coat the economic world: Regional strategies to make science useful". Technovation 30: $508-518$.

Jongbloed, B., Enders, J., and Salerno, C. 2008. "Higher education and its communities: interconnections, interdependencies and a research agenda". Higher Education 56: 303-324.

Kitagawa, F., Sánchez Barrioluengo, M., and Uyarra, E. 2016. "Third mission as institutional strategies: Between isomorphic forces and heterogeneous pathways". Science and Public Policy 43(6): 736-750. doi: 10.1093/scipol/scw015.

Kruskal, J.B. 1964. "Multidimensional Scaling by Optimizing Goodness of Fit to a Non-Metric Hypothesis". Psychometrika 29(1): 1-27.

Kruskal, J.B., and Wish, M. 1978. Multidimensional Scaling. London: Sage.

Labanauskis, R. and Ginevičius, R. 2017. "Role of stakeholders leading to development of higher education services". Engineering Management in Production and Services 9(3): 63-75.

Lepori, B., Huisman, J., and Seeber, M. 2014. "Convergence and differentiation processes in Swiss higher education: an empirical analysis". Studies in Higher Education 39(2): 197-218. doi: 10.1080/03075079.2011.647765. 
Mainardes, E., Alves, H., and Raposo, M. 2013. "Identifying stakeholders in a Portuguese university: a case study". Revista de Educación 362: 429-457.

Mampaey, J., and Huisman, J. 2016. "Defensive stakeholder management in European universities: an institutional logics perspective". Studies in Higher Education 41(12): 2218-2231. doi: 10.1080/03075079.2015.1029904.

Mar-Molinero, C., and Mingers, J. 2007. "Mapping MBA Programmes: An alternative analysis". Journal of the Operational Research Society 58(1): 874-886.

Marshall, S.J. 2018. "Internal and External Stakeholders in Higher Education". In Shaping the University of the Future, edited by Marshall, S.J., 77-102. Singapore: Springer.

Molas-Gallart, J., Salter, A., Patel, P., Scott, A., and Duran, X. 2002. Measuring Third Stream Activities. Final Report to the Russell Group of Universities. Brighton: SPRU, University of Sussex.

Ntshoe, I. 2015. "Essaying purposes and specialisations of institutional types in knowledge production". Studies in Higher Education 40(4): 676-689. doi: 10.1080/03075079.2013.842222.

Olssen, M., and Peters, M.A. 2005. "Neoliberalism, higher education and the knowledge economy: from the free market to knowledge capitalism”. Journal of Education Policy 20(3): 313-345.

Osborne, C., Davies, J., and Garnett, J. 1998. "Guiding the student to the centre of the stakeholder curriculum: independent and work-based learning at Middlesex University". In Capability and quality in higher education, edited by J. Stephenson, and M. Yorke, 85-94. London: Kogan Page.

Perez-Esparrells, C., and Torre, E.M. 2013. "Fundraising in Higher Education Institutions: a Strategy for University Enhancement”. In Resilient Universities, Confronting Changes in a Challenging World, edited by J.E. Karlsen, and R. Pritchard, 323-348. Oxford: Peter Lang.

Ramirez-Corcoles, Y., and Manzaneque-Lizano, M. 2015. "The relevance of intellectual capital disclosure: empirical evidence from Spanish universities". Knowledge Management Research \& Practice 13(1): 31-44.

Rosli, A., and Rossi, F. 2015. "Assessing the impact of knowledge transfer policies: An international comparison of models and indicators of universities' knowledge transfer 
performance". In Handbook of Politics and Technology, edited by U. Hilpert, 438-454. Abingdon, Oxon: Routledge.

Rossi, F. 2018. "The drivers of efficient knowledge transfer performance: evidence from British universities". Cambridge Journal of Economics 42(3): 729-755.

Rossi, F. 2010. "Massification, competition and organizational diversity in higher education: evidence from Italy". Studies in Higher Education 35(3): 277-300.

Russell, P.F., and Rao, T.R. 1940. "On habitat and association of species of anopheline larvase in south-eastern Madras". Journal of the Malaria Institute of India 3: $153-178$.

Sagarra, M., Mar-Molinero, C., and Agasisti, T. 2017. "Exploring the efficiency of Mexican universities: Integrating Data Envelopment Analysis and Multidimensional Scaling”. Omega 67: 123-133.

Sagarra, M., Mar-Molinero, C., and Rodriguez-Regordosa, H. 2015. "Evaluating the success of educational policy in Mexican Higher Education". Higher Education 69(3): 449-469.

Schimank, U. 2005. 'New Public Management' and the academic profession: reflections on the German situation". Minerva 43(4): 361-376.

Schoen, A., Laredo, P., Bellon, B., and Sanchez, P. 2007. Observatory of European University: PRIME Position Paper, version March 2007. Available at: http://www.primenoe.org/Local/prime/dir/Projects/OEU/OEU\%20position\%20paper\%20m arch2007.pdf

Siegel, D., Waldman, D., and Link, A. 2003. “Assessing the impact of organizational practices on the relative productivity of university technology transfer offices: an exploratory study". Research Policy 32: 27-48.

Spaapen, J., Dijstelbloem, H., and Wamelink, F. 2007. Evaluating Research in Context: a Method for Comprehensive Assessment. The Hague: COS.

Tetrevova, L., and Sabolova, V. 2010. University Stakeholder Management. Latest Trends on Engineering Education. Mathematics and Computers in Science and Engineering.

Thursby, J. G., and Kemp, S. 2002. "Growth and Productive Efficiency of University Intellectual Property Licensing”. Research Policy 31: 109-124. 
Appendix 1. Universities included in the sample by cluster.

\begin{tabular}{|c|c|c|}
\hline \multirow{9}{*}{$\begin{array}{l}\text { Cluster } \\
\text { Cluster 1 } \\
\text { (SHRI) }\end{array}$} & University & Acronym \\
\hline & The University of Bristol & bristol \\
\hline & The University of Cambridge & cam \\
\hline & The Institute of Cancer Research & icr \\
\hline & Imperial College of Science, Technology and Medicine & imperial \\
\hline & London School of Hygiene and Tropical Medicine & lshtm \\
\hline & The University of Oxford & ox \\
\hline & The University of St Andrews & standrews \\
\hline & University College London & $\mathrm{ucl}$ \\
\hline \multirow{50}{*}{$\begin{array}{l}\text { Cluster } 2 \\
\text { (MPRI) }\end{array}$} & The University of Aberdeen & abdn \\
\hline & Aberystwyth University & aber \\
\hline & Aston University & aston \\
\hline & Bangor University & bangor \\
\hline & The University of Bath & bath \\
\hline & The Queen's University of Belfast & qub \\
\hline & Birkbeck College & bbk \\
\hline & The University of Birmingham & birmingham \\
\hline & The University of Bradford & brad \\
\hline & Brunel University & brunel \\
\hline & The University of Buckingham & $\mathrm{ub}$ \\
\hline & Cardiff University & cardiff \\
\hline & The City University & city \\
\hline & Cranfield University & cranfield \\
\hline & The University of Dundee & dundee \\
\hline & University of Durham & dur \\
\hline & The University of East Anglia & uea \\
\hline & The University of Edinburgh & ed \\
\hline & The University of Essex & essex \\
\hline & The University of Exeter & exeter \\
\hline & University of South Wales & glam \\
\hline & The University of Glasgow & gla \\
\hline & Heriot-Watt University & hw \\
\hline & University of Hertfordshire & herts \\
\hline & The University of Hull & hull \\
\hline & The University of Keele & keele \\
\hline & The University of Kent & kent \\
\hline & King's College London & $\mathrm{kcl}$ \\
\hline & The University of Lancaster & lancaster \\
\hline & The University of Leeds & leeds \\
\hline & The University of Leicester & leicester \\
\hline & The University of Liverpool & liverpool \\
\hline & London School of Economics and Political Science & lse \\
\hline & Loughborough University & lboro \\
\hline & The University of Manchester & um \\
\hline & The University of Newcastle-upon-Tyne & $\mathrm{ncl}$ \\
\hline & The University of Nottingham & nottingham \\
\hline & Oxford Brookes University & brookes \\
\hline & The University of Plymouth & plymouth \\
\hline & Queen Mary and Westfield College & qmul \\
\hline & The University of Reading & reading \\
\hline & Royal Holloway and Bedford New College & rh \\
\hline & The School of Oriental and African Studies & soas \\
\hline & The University of Sheffield & sheffield \\
\hline & The University of Southampton & soton \\
\hline & The University of Stirling & stir \\
\hline & The University of Strathclyde & strath \\
\hline & The University of Surrey & surrey \\
\hline & The University of Sussex & sussex \\
\hline & Swansea University & swan \\
\hline
\end{tabular}




\begin{tabular}{|c|c|c|}
\hline Cluster & University & Acronym \\
\hline$\overline{\text { Cluster } 2}$ & University of Ulster & ulster \\
\hline$(M P R I)$ & The University of Warwick & warwick \\
\hline & The University of Wolverhampton & wlv \\
\hline & The University of York & york \\
\hline$\overline{\text { Cluster } 3}$ & University of Abertay Dundee & abertay \\
\hline$(\boldsymbol{P T I})$ & Anglia Ruskin University & anglia \\
\hline & University of Bedfordshire & beds \\
\hline & Birmingham City University & bcu \\
\hline & University College Birmingham & ucb \\
\hline & The University of Bolton & bolton \\
\hline & Bournemouth University & bu \\
\hline & The University of Brighton & brighton \\
\hline & Buckinghamshire New University & bucks \\
\hline & The University of Central Lancashire & uclan \\
\hline & University of Chester & chester \\
\hline & Coventry University & coventry \\
\hline & De Montfort University & $\mathrm{dmu}$ \\
\hline & University of Derby & derby \\
\hline & The University of East London & uel \\
\hline & Edinburgh Napier University & napier \\
\hline & Glasgow Caledonian University & gcu \\
\hline & University of Gloucestershire & glos \\
\hline & Glynd?r University & glyndwr \\
\hline & The University of Greenwich & gre \\
\hline & Harper Adams University College & hau \\
\hline & The University of Huddersfield & hud \\
\hline & Kingston University & kingston \\
\hline & Leeds Metropolitan University & leedsbeckett \\
\hline & The University of Lincoln & lincoln \\
\hline & Liverpool John Moores University & limu \\
\hline & London Metropolitan University & londonmet \\
\hline & London South Bank University & lsbu \\
\hline & The Manchester Metropolitan University & $\mathrm{mmu}$ \\
\hline & Middlesex University & $\mathrm{mdx}$ \\
\hline & The University of Northampton & northampton \\
\hline & The University of Northumbria at Newcastle & northumbria \\
\hline & The Nottingham Trent University & ntu \\
\hline & The Open University & open \\
\hline & The University of Portsmouth & port \\
\hline & Queen Margaret University, Edinburgh & qmu \\
\hline & Ravensbourne & ravensbourne \\
\hline & The Robert Gordon University & rgu \\
\hline & Royal Agricultural College & $\mathrm{rau}$ \\
\hline & The Royal Veterinary College & rvc \\
\hline & St George's Hospital Medical School & sgul \\
\hline & The University of Salford & salford \\
\hline & Sheffield Hallam University & shu \\
\hline & Southampton Solent University & solent \\
\hline & Staffordshire University & staffs \\
\hline & University Campus Suffolk & ucs \\
\hline & The University of Sunderland & sunderland \\
\hline & Teesside University & tees \\
\hline & University of the West of England, Bristol & uwe \\
\hline & The University of the West of Scotland & uws \\
\hline & The University of West London & uwl \\
\hline & The University of Westminster & westminster \\
\hline & The University of Worcester & worcester \\
\hline & Writtle College & writtle \\
\hline & SRUC & sruc \\
\hline
\end{tabular}




\begin{tabular}{|c|c|c|}
\hline \multirow{41}{*}{$\begin{array}{l}\text { Cluster } \\
\text { Cluster } 4 \\
(\text { AHTI })\end{array}$} & University & Acronym \\
\hline & Bath Spa University & bathspa \\
\hline & Bishop Grosseteste University College Lincoln & bgu \\
\hline & The Arts University College at Bournemouth & $\mathrm{aub}$ \\
\hline & Canterbury Christ Church University & $\operatorname{cccu}$ \\
\hline & Cardiff Metropolitan University & cardiffmet \\
\hline & Central School of Speech and Drama & cssd \\
\hline & The University of Chichester & chi \\
\hline & Conservatoire for Dance and Drama & cdd \\
\hline & Courtauld Institute of Art & courtauld \\
\hline & University for the Creative Arts & ucreative \\
\hline & University of Cumbria & cumbria \\
\hline & Edge Hill University & edgehill \\
\hline & University College Falmouth & falmouth \\
\hline & Glasgow School of Art & gsa \\
\hline & Goldsmiths College & gold \\
\hline & Guildhall School of Music and Drama & gsmd \\
\hline & Heythrop College & heythrop \\
\hline & Institute of Education & ioe \\
\hline & Leeds Trinity University College & leedstrinity \\
\hline & Liverpool Hope University & hope \\
\hline & The Liverpool Institute for Performing Arts & lipa \\
\hline & University of the Arts, London & arts \\
\hline & Newman University College & newman \\
\hline & Norwich University College of the Arts & nua \\
\hline & University College Plymouth St Mark and St John & marjon \\
\hline & Roehampton University & roehampton \\
\hline & Rose Bruford College & bruford \\
\hline & Royal Academy of Music & ram \\
\hline & Royal College of Art & rca \\
\hline & Royal College of Music & $\mathrm{rcm}$ \\
\hline & Royal Northern College of Music & rncm \\
\hline & St Mary's University College & stmarys \\
\hline & St Mary's University College, Twickenham & stmaryst \\
\hline & Stranmillis University College & stran \\
\hline & Trinity Laban Conservatoire of Music and Dance & trinitylaban \\
\hline & University of Wales Trinity Saint David & trinitysaintdavid \\
\hline & The University of Winchester & winchester \\
\hline & York St John University & yorksj \\
\hline & Leeds College of Art & lca \\
\hline & Roval Conservatoire of Scotland & $\operatorname{res}$ \\
\hline
\end{tabular}




\section{Appendix 2. Pearson correlation between activity and resource variables.}

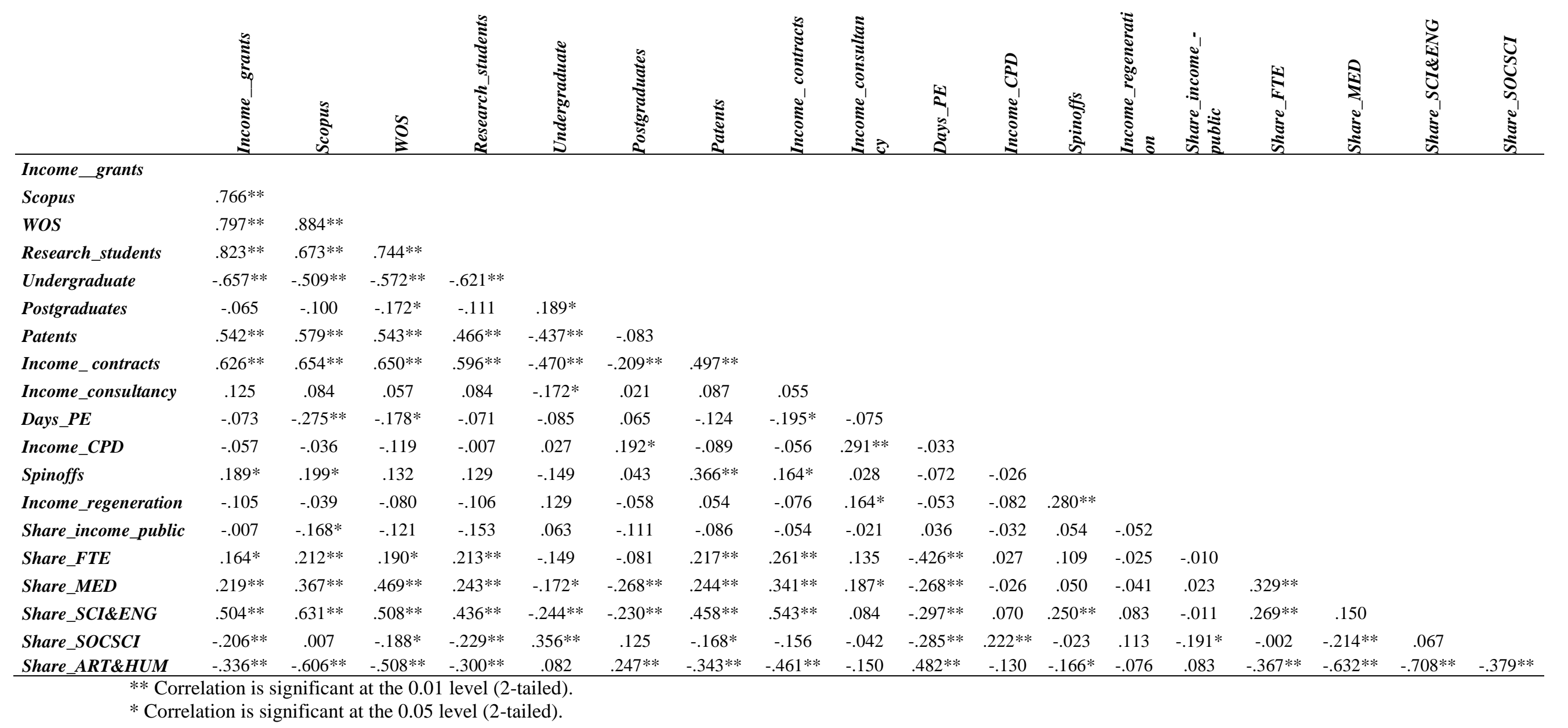


Table 1. Main HEI's external stakeholders and their roles.

\begin{tabular}{|c|c|c|}
\hline $\begin{array}{l}\text { HEI stakeholders } \\
\text { types }\end{array}$ & Nature of stakeholders & Role of HEI stakeholders \\
\hline Students & $\begin{array}{l}\text { Students, their associates (e.g. students' } \\
\text { parents) and alumni (individuals and } \\
\text { organisations). }\end{array}$ & $\begin{array}{l}\text { End user } \\
\text { Professional user } \\
\text { Donors } \\
\text { Prestige communication }\end{array}$ \\
\hline \multirow[t]{6}{*}{$\begin{array}{l}\text { Industry and } \\
\text { government }\end{array}$} & $\begin{array}{l}\text { Governing entities and regulators: e.g. } \\
\text { EU, Central (Federal), Regional or Local }\end{array}$ & $\begin{array}{l}\text { Policy maker } \\
\text { Representative of other stakeholders } \\
\text { Funder }\end{array}$ \\
\hline & Research Councils & $\begin{array}{l}\text { Professional user } \\
\text { Funder } \\
\text { Representative of other stakeholders } \\
\text { Partners, collaborators, sponsors and } \\
\text { project funders }\end{array}$ \\
\hline & $\begin{array}{l}\text { National and international university } \\
\text { rankings }\end{array}$ & $\begin{array}{l}\text { Professional user } \\
\text { Prestige communication }\end{array}$ \\
\hline & Other universities & Competitors and collaborators \\
\hline & Patent Offices & $\begin{array}{l}\text { Professional user } \\
\text { Partners, collaborators, sponsors and } \\
\text { project funders }\end{array}$ \\
\hline & $\begin{array}{l}\text { Technology centres and scientific and } \\
\text { technological parks }\end{array}$ & $\begin{array}{l}\text { Professional user } \\
\text { Partners, collaborators, sponsors and } \\
\text { project funders }\end{array}$ \\
\hline \multirow[t]{2}{*}{ Employers } & Corporate co-sponsors of research & $\begin{array}{l}\text { Professional user } \\
\text { Partners, collaborators and sponsors }\end{array}$ \\
\hline & Alliances and consortia & $\begin{array}{l}\text { Professional user } \\
\text { Partners and collaborators }\end{array}$ \\
\hline \multirow[t]{3}{*}{ Community } & $\begin{array}{l}\text { Third sector (foundations, church } \\
\text { sponsors, etc.) }\end{array}$ & $\begin{array}{l}\text { Professional user } \\
\text { Donors }\end{array}$ \\
\hline & Secondary education centres & Suppliers \\
\hline & Citizens and individual groups & $\begin{array}{l}\text { End users } \\
\text { Donors }\end{array}$ \\
\hline
\end{tabular}

Source: authors' elaboration based on Spaapen, Dijstelbloem and Wamelink (2007) and Perez-Esparrells and Torre (2013, p.336). 
Table 2. Variables used to identify HEIs' activity profiles.

\begin{tabular}{|c|c|c|c|c|c|c|c|}
\hline & $N$. & Variable ID & Variable description & $\operatorname{Min}$ & $\operatorname{Max}$ & Mean & $\begin{array}{l}\text { St. } \\
\text { Dev }\end{array}$ \\
\hline \multirow[t]{4}{*}{$\begin{array}{l}\text { Research } \\
\text { engagement }\end{array}$} & 1 & Income_grants & $\begin{array}{l}\text { Income from research grants / Full Time } \\
\text { Equivalent Faculty (FTEF) }\end{array}$ & 0.00 & 27.91 & 5.87 & 5.82 \\
\hline & 2 & Scopus & N. papers (Scopus) / FTEF & 0.00 & 2.89 & 0.55 & 0.45 \\
\hline & 3 & WOS & N. papers (WoS) / FTEF & 0.00 & 3.13 & 0.50 & 0.50 \\
\hline & 4 & Research_students & N. research students / total enrolment & 0.00 & 0.43 & 0.05 & 0.06 \\
\hline \multirow{2}{*}{$\begin{array}{l}\text { Teaching } \\
\text { engagement }\end{array}$} & 5 & Undergraduate & Enrolment (undergraduate) / FTEF & 0.00 & 43.31 & 11.21 & 6.44 \\
\hline & 6 & Postgraduates & Enrolment (postgraduate) / FTEF & 0.00 & 10.00 & 3.15 & 1.81 \\
\hline Third & 7 & Patents & N. patent applications / FTEF & 0.00 & 0.04 & 0.01 & 0.01 \\
\hline mission & 8 & Income_contracts & Income from research contracts / FTEF & 0.00 & 21.54 & 2.98 & 3.70 \\
\hline \multirow[t]{5}{*}{ engagement } & 9 & Income_consultancy & Income from consultancy contracts / FTEF & 0.00 & 18.40 & 1.83 & 2.60 \\
\hline & 10 & Days_PE & $\begin{array}{l}\text { N. academic days spent on public } \\
\text { engagement / FTEF }\end{array}$ & 0.00 & 45.14 & 1.58 & 4.79 \\
\hline & 11 & Income_CPD & $\begin{array}{l}\text { Income from Continuing Professional } \\
\text { Development courses / FTEF }\end{array}$ & 0.00 & 19.91 & 3.23 & 3.27 \\
\hline & 12 & Spinoffs & $\begin{array}{l}\text { N. current year Spinoffs with some HEI } \\
\text { ownership / FTEF }\end{array}$ & 0.00 & 0.01 & 0.00 & 0.00 \\
\hline & 13 & Income_regeneration & Regeneration income / FTEF & -0.19 & 8.61 & 0.91 & 1.72 \\
\hline \multirow{2}{*}{$\begin{array}{l}\text { Funding } \\
\text { structure }\end{array}$} & 14 & Share_income_public & Total grants / total income & 0.00 & 0.69 & 0.22 & 0.11 \\
\hline & 15 & Share_FTE & FTEF / total faculty & 0.21 & 1.55 & 0.81 & 0.18 \\
\hline \multirow[t]{4}{*}{ Subject mix } & 16 & Share_MED & $\%$ FTEF in medicine & 0.00 & 1.00 & 0.22 & 0.19 \\
\hline & 17 & Share_SCI\&ENG & $\%$ FTEF in science and engineering & 0.00 & 0.75 & 0.23 & 0.17 \\
\hline & 18 & Share_SOCSCI & $\%$ FTEF in the social sciences & 0.00 & 0.81 & 0.21 & 0.14 \\
\hline & 19 & Share_ART\&HUM & $\%$ FTEF in the arts and humanities & 0.00 & 1.00 & 0.35 & 0.30 \\
\hline
\end{tabular}


Table 3. Variables used to identify HEIs' strategic profiles for stakeholder prioritisation.

\begin{tabular}{llll} 
& N. & Variable ID & Variable description \\
\hline Priority stakeholders by & 1 & Commercial & Commercial private business \\
sector & 2 & Non_commercial & Non-commercial social, community and cultural organisations \\
& 3 & Public_sector & Public sector (commercial and non-commercial) \\
\hline Priority stakeholders by & 4 & Students & Stakeholders: students \\
nature & 5 & Employers & Stakeholders: employers \\
& 6 & Industry & Stakeholders: industry \\
& 7 & Communities & Stakeholders: local communities \\
\hline Priority stakeholders by & 8 & National and & National and/or international \\
geographic location & & international & \\
& 9 & Regional & Regional \\
& 10 & Local & Local \\
\hline
\end{tabular}


Table 4. Clustering of HEIs based on MDS variables.

\begin{tabular}{|c|c|c|c|c|c|c|c|c|}
\hline \multirow[b]{2}{*}{ Variable ID } & \multicolumn{2}{|c|}{ Cluster 1 (SHRI) } & \multicolumn{2}{|c|}{ Cluster 2 (MPRI) } & \multicolumn{2}{|c|}{ Cluster 3 (PTI) } & \multicolumn{2}{|c|}{ Cluster 4 (AHTI) } \\
\hline & Mean & Std. Dev. & Mean & Std. Dev. & Mean & Std. Dev. & Mean & Std. Dev. \\
\hline Income_grants & 18.37 & 5.10 & 9.61 & 3.62 & 2.27 & 1.96 & 3.27 & 5.56 \\
\hline Scopus & 1.40 & 0.64 & 0.91 & 0.25 & 0.37 & 0.19 & 0.14 & 0.22 \\
\hline WOS & 1.65 & 0.63 & 0.81 & 0.27 & 0.27 & 0.32 & 0.14 & 0.25 \\
\hline Research_students & 0.23 & 0.11 & 0.07 & 0.03 & 0.02 & 0.01 & 0.02 & 0.04 \\
\hline Undergraduate & 2.13 & 1.92 & 7.47 & 3.62 & 16.00 & 5.99 & 11.48 & 5.40 \\
\hline Postgraduates & 1.31 & 0.47 & 2.87 & 1.30 & 3.22 & 1.48 & 3.81 & 2.54 \\
\hline Patents & 0.02 & 0.01 & 0.01 & 0.01 & 0.00 & 0.00 & 0.00 & 0.00 \\
\hline Income_contracts & 10.91 & 5.92 & 5.03 & 3.38 & 1.54 & 1.56 & 0.61 & 1.40 \\
\hline Income_consultancy & 1.68 & 1.12 & 2.24 & 2.07 & 1.85 & 3.20 & 1.26 & 2.51 \\
\hline Days_PE & 0.31 & 0.30 & 0.35 & 0.48 & 0.52 & 0.63 & 4.97 & 8.66 \\
\hline Income_CPD & 1.64 & 1.31 & 2.88 & 3.44 & 4.53 & 3.17 & 2.23 & 2.90 \\
\hline Spinoffs & 0.00 & 0.00 & 0.00 & 0.00 & 0.00 & 0.00 & 0.00 & 0.00 \\
\hline Income_regeneration & 0.06 & 0.11 & 1.47 & 2.44 & 0.68 & 1.01 & 0.66 & 1.27 \\
\hline Share_income_public & 0.18 & 0.03 & 0.20 & 0.08 & 0.23 & 0.13 & 0.23 & 0.13 \\
\hline Share_FTE & 0.93 & 0.03 & 0.84 & 0.13 & 0.81 & 0.15 & 0.74 & 0.27 \\
\hline Share_MED & 0.43 & 0.19 & 0.24 & 0.14 & 0.28 & 0.21 & 0.06 & 0.09 \\
\hline Share_SCI\&ENG & 0.41 & 0.12 & 0.36 & 0.14 & 0.22 & 0.11 & 0.04 & 0.06 \\
\hline Share_SOCSCI & 0.07 & 0.06 & 0.23 & 0.13 & 0.28 & 0.13 & 0.11 & 0.12 \\
\hline Share_ART\&HUM & 0.09 & 0.08 & 0.17 & 0.09 & 0.23 & 0.12 & 0.80 & 0.18 \\
\hline$N$ & & 8 & & 54 & & 55 & & 40 \\
\hline
\end{tabular}


Table 5. Results of ProFit analysis of qualitative MDS.

\begin{tabular}{|c|c|c|c|c|c|c|c|}
\hline & Variable ID & $\begin{array}{c}\text { Dim } 1 \\
\text { Not } \\
\text { prioritising } \\
\text { industry }\end{array}$ & $\begin{array}{c}\text { Dim } 2 \\
\text { Prioritising } \\
\text { local } \\
\text { community }\end{array}$ & $\begin{array}{c}\text { Dim } 3 \\
\text { Prioritising } \\
\text { employers }\end{array}$ & $\begin{array}{c}\text { Dim 4 } \\
\text { Prioritising } \\
\text { students }\end{array}$ & $\begin{array}{c}\text { Dim } 5 \\
\text { Not } \\
\text { prioritising } \\
\text { non- } \\
\text { commercial }\end{array}$ & $R^{2}$ \\
\hline \multirow{3}{*}{$\begin{array}{l}\text { Priority } \\
\text { stakeholders } \\
\text { by sector }\end{array}$} & Commercial & -0.793 & 0.403 & -0.055 & 0.446 & 0.083 & 0.90 \\
\hline & Non_commercial & 0.377 & 0.034 & 0.453 & 0.086 & -0.803 & 0.54 \\
\hline & Public_sector & 0.446 & -0.427 & -0.538 & -0.561 & 0.124 & 0.95 \\
\hline \multirow{4}{*}{$\begin{array}{l}\text { Priority } \\
\text { stakeholders } \\
\text { by nature }\end{array}$} & Students & 0.541 & -0.191 & -0.184 & 0.760 & 0.244 & 0.94 \\
\hline & Employers & 0.025 & -0.765 & 0.620 & 0.001 & -0.172 & 0.93 \\
\hline & Industry & -0.596 & 0.182 & -0.455 & -0.455 & -0.445 & 0.86 \\
\hline & Communities & 0.350 & 0.437 & 0.586 & -0.411 & 0.418 & 0.96 \\
\hline \multirow{3}{*}{$\begin{array}{l}\text { Priority } \\
\text { stakeholders } \\
\text { by geographic } \\
\text { location }\end{array}$} & $\begin{array}{l}\text { National and } \\
\text { international }\end{array}$ & -0.155 & -0.710 & 0.687 & -0.023 & 0.001 & 0.91 \\
\hline & Regional & 0.689 & 0.027 & -0.440 & 0.302 & 0.489 & 0.40 \\
\hline & Local & 0.506 & 0.611 & 0.445 & -0.232 & -0.344 & 0.87 \\
\hline
\end{tabular}


Table 6. HEIs clusters and nature of stakeholders.

\begin{tabular}{llcccc} 
& Variable ID & Cluster 1 & Cluster 2 & Cluster 3 & Cluster 4 \\
PTI & SHRI & MPRI & PTI \\
\hline Priority stakeholders by sector & Commercial & $\mathbf{8 7 . 5 \%}$ & $\mathbf{6 8 . 5 \%}$ & $\mathbf{4 9 . 1 \%}$ & $22.5 \%$ \\
& Non_commercial & $12.5 \%$ & $0.0 \%$ & $14.5 \%$ & $\mathbf{4 2 . 5 \%}$ \\
& Public_sector & $12.5 \%$ & $31.5 \%$ & $\mathbf{5 2 . 7 \%}$ & $32.5 \%$ \\
\hline Priority stakeholders by nature & Students & $25.0 \%$ & $38.9 \%$ & $\mathbf{6 5 . 5 \%}$ & $\mathbf{9 2 . 5 \%}$ \\
& Employers & $\mathbf{5 0 . 0 \%}$ & $\mathbf{4 2 . 6 \%}$ & $\mathbf{5 6 . 4 \%}$ & $\mathbf{6 2 . 5 \%}$ \\
& Industry & $\mathbf{1 0 0 . 0 \%}$ & $\mathbf{9 6 . 3 \%}$ & $\mathbf{7 8 . 2 \%}$ & $\mathbf{5 5 . 0 \%}$ \\
& Communities & $0.0 \%$ & $24.1 \%$ & $\mathbf{3 2 . 7 \%}$ & $\mathbf{4 5 . 0 \%}$ \\
\hline Priority stakeholders by & National and international & $\mathbf{5 0 . 0 \%}$ & $31.5 \%$ & $25.5 \%$ & $37.5 \%$ \\
geographic location & Regional & $25.0 \%$ & $\mathbf{4 6 . 3 \%}$ & $\mathbf{7 8 . 2 \%}$ & $\mathbf{7 2 . 5 \%}$ \\
& Local & $12.5 \%$ & $16.7 \%$ & $\mathbf{4 3 . 6 \%}$ & $\mathbf{5 0 . 0 \%}$ \\
\hline
\end{tabular}


Table 7. Results from the multinomial logistic regression on resource and activity profiles and stakeholder prioritisation strategies.

\begin{tabular}{|c|c|c|c|c|}
\hline Cluster & Variables & $b$ & Srd. Error & $\begin{array}{l}\text { Marginal } \\
\text { effects }\end{array}$ \\
\hline \multirow{6}{*}{$1(S H R I)$} & Not prioritising industry & $-4.406 * * *$ & 1.167 & -0.084 \\
\hline & Prioritising local community & -1.329 & 1.455 & -0.025 \\
\hline & Prioritising employers & -2.026 & 1.567 & -0.039 \\
\hline & Prioritising students & -1.144 & 1.556 & -0.025 \\
\hline & Not prioritising non-commercial & -0.706 & 1.791 & -0.005 \\
\hline & Constant & $-3.068 * * *$ & 0.712 & \\
\hline \multirow[t]{6}{*}{$2(M P R I)$} & Not prioritising industry & $-2.341 * * *$ & 0.596 & -0.649 \\
\hline & Prioritising local community & -0.022 & 0.591 & 0.053 \\
\hline & Prioritising employers & $-1.524 * *$ & 0.760 & -0.465 \\
\hline & Prioritising students & -0.978 & 0.894 & -0.356 \\
\hline & Not prioritising non-commercial & 0.060 & 1.130 & 0.195 \\
\hline & Constant & -0.258 & 0.220 & \\
\hline \multicolumn{5}{|c|}{$3(P T I)$ is the base outcome } \\
\hline \multirow[t]{6}{*}{$4(A H T I)$} & Not prioritising industry & $2.668 * * *$ & 0.762 & 0.483 \\
\hline & Prioritising local community & -0.874 & 0.727 & -0.106 \\
\hline & Prioritising employers & $2.394 * * *$ & 0.916 & 0.396 \\
\hline & Prioritising students & $2.583 * *$ & 1.177 & 0.388 \\
\hline & Not prioritising non-commercial & $-3.250^{*}$ & 1.887 & -0.417 \\
\hline & Constant & $-1.147 * * *$ & 0.327 & \\
\hline$N$ & 157 & & & \\
\hline LR Chi2 & $85.59 * * *$ & & & \\
\hline Log likelihood & -151.0344 & & & \\
\hline Pseudo R2 & 0.2208 & & & \\
\hline
\end{tabular}


Figure 1. Institutional resources, activity profiles and stakeholders.

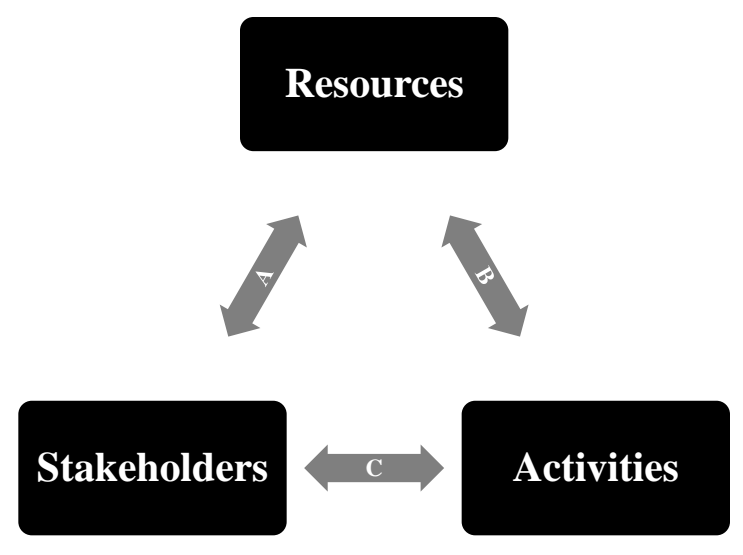

